\title{
Protection of Mild Steel Corrosion in Sulphuric Acid Environment Using Wheat Starch
}

\author{
Nwanonenyi S.C. ${ }^{* 1, a}$, Ogbobe O. ${ }^{1, b}$ and Oguzie E.E. ${ }^{2, c}$ \\ ${ }^{* 1}$ Department of Polymer and Textile Engineering, Federal University of Technology, Owerri \\ ${ }^{2}$ Electrochemistry and Materials Science Research Laboratory, Department of Chemistry, \\ Federal University of Technology, Owerri Imo State, Nigeria. P.M. B. 1526 \\ *asimyn22@yahoo.co.uk, bogbobeokoro1@yahoo.com, 'oguziemeka@yahoo.com
}

Keywords: Wheat starch, mild steel, corrosion, inhibition, activation energy and heat adsorption

\begin{abstract}
The corrosion of mild steel in $0.5 \mathrm{M} \mathrm{H}_{2} \mathrm{SO}_{4}$ acid solution and the inhibition process by wheat starch (WS) was investigated using weight loss and potentiodynamic polarization measurement techniques respectively. Gravimetric results revealed that there is significant reduction in the corrosion rate of mild steel in the presence of inhibited solution compared to blank solution, and also the inhibition efficiency was found to depend on the concentration of the WS. Data on potentiodynamic polarization results confirmed that WS exhibited mixed type inhibition behaviour, though the cathodic effect was more pronounced. The mode of WS adsorption on the corroding metal surface followed Langmuir isotherm model. In addition, the trend of inhibition efficiency with temperature, activation energy and heat of adsorption parameters revealed a strong interaction between the WS constituents and the corroding metal surface, thus indicating that WS lowered the corrosion process by blanketing the mild steel surface through chemical adsorption mechanism. The mechanism of inhibition was discussed in the light of the chemical structure of starch.
\end{abstract}

\section{Introduction}

Metals and alloys are enjoying wider acceptance in structural and fabricating applications in the industrial sectors due to excellent mechanical performance or behaviour associated with them. Corrosion of metal and alloy is a degradation of metal and alloy as a result of environment surrounding them. It is a non preventable phenomenon but can be controlled through the use of some macromolecules [1-10], organic compounds [11-16] or extracts from natural plants [17-23] as corrosion inhibitors. Polymers are macromolecules formed by the repetition of smaller molecules (monomers) that are covalently bonded together. They are widely used as plastics, textile materials, rubber, adhesives, drilling mud, binders and thickeners in surface coating, dyes, pigments, etc. because of ease of processing and modifying the physical and chemical properties of polymers. The utilization of some polymeric materials (natural and synthetic) in controlling corrosion of metals and alloys in various aggressive environments has gained wider acceptance as a result of some inherent properties of the polymers which include: biodegradability, non-toxicity, readily availability, low cost, renewability, water solubility, etc. Polymers and their blends are preferred more than simple organic compounds as inhibitors for corrosion control because they possess multiple functional and substituent groups either in their back bone or side chains which act as regions at which electrons are donated or accepted from surface charge on the metal. Some organic compounds are effective corrosion inhibitors due to presence of hetero-atoms (nitrogen, sulphur, oxygen, etc.) combination of the atoms in their molecular structures [24-27]. Polymers functioned as effective corrosion inhibitors even at low concentrations [28] by forming complexes through their multiple functional and substituent groups with the metal ions which are adsorbed on metal surface and formed protective films at interface between metal and aggressive solution [29]. The inhibitive performance of polymers may be related to the molecular structure and solubility parameter of the polymers in various solvents of exposure. Recently, greater attention is being directed towards the utilization eco-friendly polymers in controlling of metal corrosion in acid 
induced environment in attempt to protect our environment, safe guard human life, save our economy and reduce the material loss. Among the eco-friendly polymers used in controlling metal corrosion in aggressive media starch (biopolymer) has not been utilized much [30-32] in the field of corrosion science despite the different sources of starch.

To the best of our knowledge, there has been any work in the scientific literature that reported the use wheat starch as the corrosion inhibitor for mild steel in sulphuric acid solution environment. This, however, informed our decision to investigate the effectiveness of wheat starch as a corrosion inhibitor. The purpose of this work is to investigate the inhibiting effect of wheat starch as corrosion inhibitor for mild steel in $0.5 \mathrm{M} \mathrm{H}_{2} \mathrm{SO}_{4}$ solution using weight loss and potentiodynamic polarization measurement techniques.

\section{Materials and Method}

\section{Metal Preparation}

The mild steel sheet (with percentage composition of $\mathrm{C}=0.06, \mathrm{Si}=0.03, \mathrm{Mn}=0.04, \mathrm{Cu}=$ $0.06, \mathrm{Cr}=0.06$, and remainder $\mathrm{Fe}$ ) was mechanically press-cut into coupons of dimension, $3 \mathrm{~cm} \mathrm{x}$ $4 \mathrm{~cm} \times 0.1 \mathrm{~cm}$. The coupons were degreased in absolute ethanol, dried in acetone and warm air and subsequently stored in moisture-free desiccators prior to use.

\section{Test Solutions}

Sulphuric acid used was of BDH AR grade. Other reagents (Sodium hydroxide, acetone and ethanol) used for the research were of Analar grade and double distilled water was used for preparation blank and inhibited solutions. The blank corrodent was $0.5 \mathrm{M} \mathrm{H}_{2} \mathrm{SO}_{4}$ solution. The inhibitor wheat starch (WS) used was processed using a method described elsewhere [33]. Test solutions of the WS were prepared in the concentration range $0.2-0.8 \mathrm{~g} / \mathrm{L}$.

\section{Weight Loss Experiment}

The cleaned and weighed coupons were suspended using glass hooks and rods in beakers containing $200 \mathrm{ml}$ test solutions. All experiments were performed under total immersion conditions of the aerated and unstirred test solutions at room temperature $\left(30 \pm 1^{\mathrm{O}} \mathrm{C}\right)$. Weight loss was determined with respect to time by retrieving the coupons from test solutions, cleaned, dried, and reweighed respectively at 24 hours intervals progressively for 5 days. The difference between the weight of the coupons at a given time and its initial weight was taken to be weight loss. All tests were run in triplicate to obtain good reproducibility data and average values for each experiment obtained were used in subsequent calculations. The value of corrosion rate was determined using Equation 1 stated below:

$$
\mathrm{CR}(\mathrm{mm} / \mathrm{yr})=\left[\frac{87.6 \times 10^{3} \Delta W}{\rho \mathrm{At}}\right]
$$

where $\Delta \mathrm{W}$ is the weight loss in gram $(\mathrm{g}), \rho$ is the density of the mild steel coupons $\left(\mathrm{g} / \mathrm{cm}^{3}\right), \mathrm{t}$ is the time of exposure $(\mathrm{h})$ and $\mathrm{A}$ is the exposed surface area of the coupons $\left(\mathrm{cm}^{2}\right)$.

The percentage inhibition efficiency (I.E \%) was calculated according to Equation 2 stated as follows:

$$
\text { I. } \mathrm{E} \%=\left[1-\frac{\mathrm{CR}_{\text {inh }}}{\mathrm{CR}_{\text {blank }}}\right] \times 100
$$

where $\mathrm{CR}_{\text {inh }}$ is the corrosion rate in the presence of inhibitor and $\mathrm{CR}_{\text {blank }}$ is the corrosion rate in absence of inhibitor.

\section{Potentiodynamic Polarization Experiment}

The potentiodynamic polarization measurements were performed in a computer controlled electrochemical workstation (PARC- 263 model). The experiments were carried out in a cylindrical glass electrolytic corrosion cell with graphite rod as counter electrode (CE), saturated calomel electrode (SCE) as reference electrode (RE) and metal coupon as the working electrode. The 
working electrode was immersed in the test solution and allowed to corrode freely for 30 min to attain open circuit potential (OCP). The potentiodynamic polarization results were obtained in the potential range of $\pm 250 \mathrm{mV}$ versus corrosion potential using linear sweep technique at a scan rate of $0.333 \mathrm{mV} / \mathrm{s}$. All the measurements were carried out at room temperature $\left(30 \pm 1^{\mathrm{O}} \mathrm{C}\right)$. The potentiodynamic polarization data was used to extrapolate the data using Power suite software. Each test was run in triplicates to verify the reproducibility of the system. The inhibition efficiency was calculated from the Equation 3 stated as follows:

$$
\text { I. } \mathrm{E}_{\mathrm{corr}}(\%)=\left[1-\left(\frac{\mathrm{I}^{1} \text { corr }}{\mathrm{I}^{2} \text { corr }}\right)\right] \times 100
$$

where $\mathrm{I}^{1}$ corr is the corrosion current in the presence of inhibitor whereas $\mathrm{I}^{2}$ corr is the corrosion current in the absence of inhibitor.

\section{Results and Discussions}

\section{Weight Loss Measurement Result:}

Effect of Inhibitor Concentration: The effect of inhibitor concentration on the corrosion rate and inhibition efficiency of mild steel in $0.5 \mathrm{M} \mathrm{H}_{2} \mathrm{SO}_{4}$ solution was studied using weight loss measurement. The results obtained depict that wheat starch decreased the corrosion rate of mild steel in the acidic solution (Table 1) and also inhibition efficiency increases with rise in the inhibition concentration at all concentrations used in the study. This could be attributed to the presence of two glucose polymers (amylopectin and amylose) and glucose in the starch molecule since starch is partially converted to glucose unit in the acid solution [34]. Furthermore, it is observed that inhibition efficiency of $90.48 \%$ was obtained at the highest inhibitor concentration. The result of inhibition efficiency exhibited by wheat starch and starch from millet reported elsewhere $[22,23]$ in regulating corrosion of metal in aggressive environment varies. The variation could be attributed to the following factors. (a) Amylose and amylopectin percentage of starch: Amylose molecule contains several thousands of glucose unit whereas amylopectin molecule has up to two million of glucose unit. Hence, in solution amylopectin molecule releases more glucose units than amylose molecule, that is, more hydroxyl groups $(-\mathrm{OH})$ and aromatic groups which are responsible for the inhibition process. (b) Availability of glucosidic linkage: Amylose molecule has 1, 4 glucosidic bonds which make the molecule possess high density, hydrolyze more slowly and become insoluble. Amylopectin molecule has 1, 6 glucosidic bonds which make the molecule to be soluble and degrade quickly because it has many end points onto which enzymes can attach. (c) Presence of hetero-atoms within the starch structure and (d) The interaction between the metal surface and constituents of starch. The values of corrosion rate and inhibition efficiency obtained from weight loss measurement at different concentrations of WS at room temperature $\left(30 \pm 1^{\circ} \mathrm{C}\right)$ are summarized in Table 1.

Table 1. Calculated values of Corrosion rate, $C_{R}(\mathrm{~mm} / \mathrm{yr})$, Inhibition efficiency (I.E \%) for Mild Steel in $0.5 \mathrm{M} \mathrm{H}_{2} \mathrm{SO}_{4}$ in the absence and presence of polyvinyl acetate from weight loss measurement at different days.

\begin{tabular}{|c|c|c|c|c|c|c|c|c|c|c|}
\hline System & \multicolumn{4}{|c|}{ Corrosion rate (mm/yr) } & \multicolumn{4}{c|}{ Inhibition efficiency (IE \%) } \\
\hline & Day1 & Day2 & Day3 & Day4 & Day5 & Day1 & Day2 & Day3 & Day4 & Day5 \\
\hline Blank & 19.22 & 15.73 & 11.24 & 9.1 & 6.77 & - & - & - & - & - \\
\hline $0.2 \mathrm{~g} / \mathrm{LWS}$ & 3.56 & 2.58 & 1.53 & 1.38 & 1.1 & 81.01 & 83.6 & 86.39 & 84.84 & 83.75 \\
\hline $\begin{array}{c}0.4 \\
\mathrm{~g} / \mathrm{LWS}\end{array}$ & 3.09 & 2.29 & 1.37 & 1.2 & 0.98 & 83.92 & 85.44 & 87.81 & 86.82 & 85.53 \\
\hline $0.6 \mathrm{~g} / \mathrm{LWS}$ & 2.83 & 2.03 & 1.26 & 1.1 & 0.89 & 85.28 & 87.09 & 88.79 & 87.92 & 86.86 \\
\hline $0.8 \mathrm{~g} / \mathrm{LWS}$ & 2.47 & 1.78 & 1.07 & 0.92 & 0.73 & 87.15 & 88.68 & 90.48 & 89.89 & 89.22 \\
\hline
\end{tabular}


Acid Concentration Effect: Fig. 1 illustrates the increasing effect of acid concentration from $0.5 \mathrm{M}$ to $3 \mathrm{M}$ on the inhibition efficiency of WS on mild steel corrosion at the highest inhibition concentration $(0.8 \mathrm{~g} / \mathrm{LWS})$ studied. It is clearly seen from this plot that increase in $\mathrm{H}_{2} \mathrm{SO}_{4}$ concentration decreased the inhibitive performance of WS from $87.15 \%$ to $60.09 \%$. It has been reported [35] that some organic inhibitors become more protonation in the presence of strong acid concentration, thus leading to better inhibition efficiency. But, the decrease in inhibition efficiency of WS with increase in acid concentration is an indication that WS did not show more protonation at increased acid concentration. Also, the decrease in inhibition efficiency of WS with increase in acid concentration could be attributed to presence of more corrosive agent in the inhibited solution which increased the aggressiveness of solution and desorption of WS on the mild steel surface.

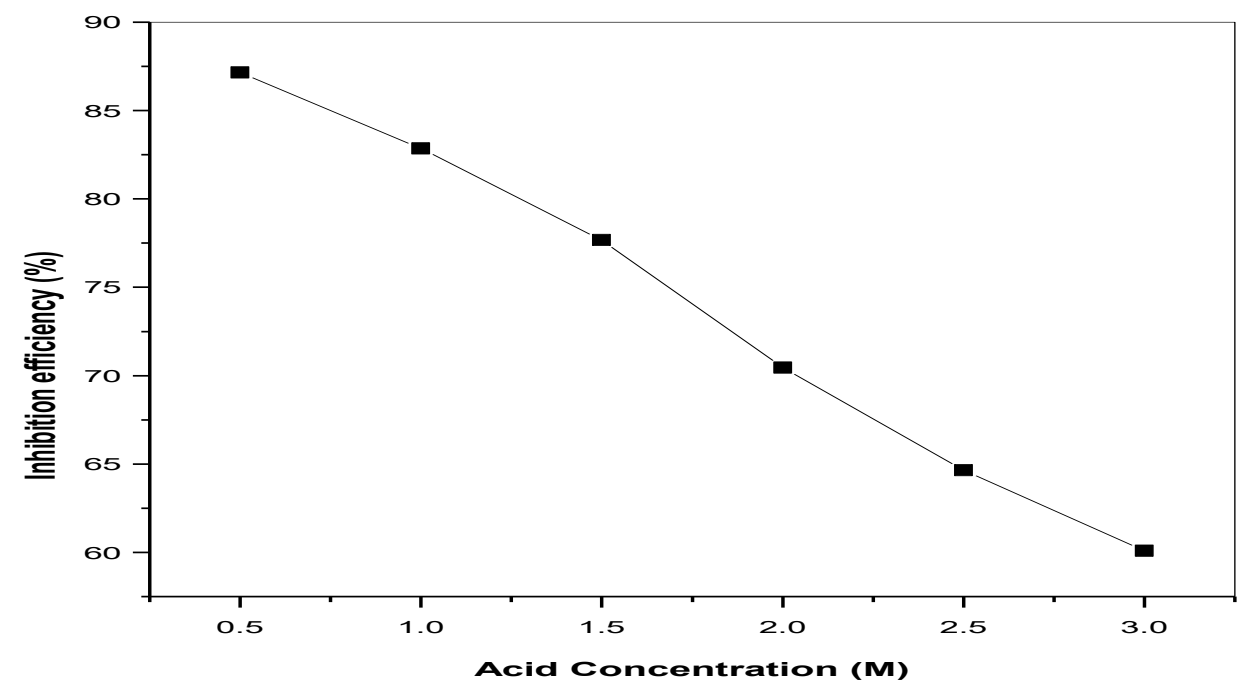

Figure 1. Plot of Inhibition efficiency against acid concentrations for mild steel corrosion in the presence $0.8 \mathrm{~g} / \mathrm{LWS}$.

Effect of Time Immersion: The stability of inhibitive behaviour of wheat starch on the corrosion of mild steel in $0.5 \mathrm{M} \mathrm{H}_{2} \mathrm{SO}_{4}$ solution was assessed on a time scale using weight loss measurement at $30 \pm 1^{\mathrm{O}} \mathrm{C}$ for 5 days immersion time. Fig. 2 showed the plot of inhibition efficiency against immersion time. It is observed from Fig. 2 that inhibition efficiency of wheat starch increased with increasing immersion time, reaching the maximum efficiency on days 3 and showed gradual decrease in the subsequent days. The increase in inhibition efficiency with time may be attributed to strong stability of the glucose components adsorbed on the mild steel surface whereas the decrease in inhibition efficiency with time reflects desorption of glucose components from the mild steel surface, resulting in a reduced surface coverage [36]. 


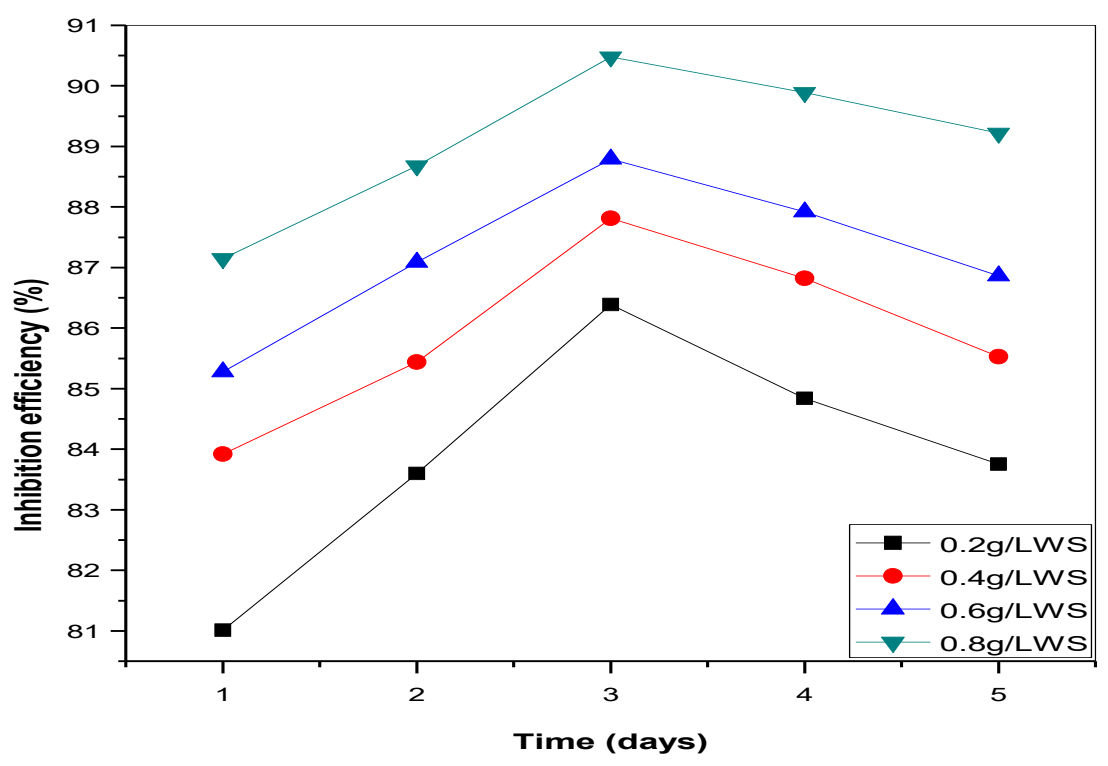

Figure 2. Effect of Immersion time on the inhibition efficiency of mild steel in $0.5 \mathrm{M} \mathrm{H}_{2} \mathrm{SO}_{4}$ in the presence of different concentrations of wheat starch.

\section{Potentiodynamic Polarization Result}

The effect of wheat starch on the anodic and cathodic reaction processes of mild steel corrosion in $0.5 \mathrm{M} \mathrm{H}_{2} \mathrm{SO}_{4}$ solution was investigated using potentiodynamic polarization measurement. The polarization curves obtained were shown in Fig. 3. It is observed that anodic and cathodic reaction processes obeyed Tafel's Law and the corrosion potential $\left(\mathrm{E}_{\text {corr }}\right)$, corrosion current densities $\left(i_{\text {corr }}\right)$, the cathodic $\left(b_{c}\right)$ and anodic $\left(b_{a}\right)$ Tafel slopes were computed from polarization curves and presented in Table 2. In addition, the values of cathodic and anodic current decreased in the presence of WS in comparison with the blank solution, thus indicating that wheat starch modified the mechanism of anodic dissolution of mild steel as well as cathodic hydrogen gas evolution. The observed shift in corrosion potential $\left(\mathrm{E}_{\mathrm{corr}}\right)$ was towards the negative direction, suggesting that addition of WS had a more pronounced cathodic effect which is in agreement with the reports elsewhere [37]. The trend increased with increased concentration of the WS. The displacement of $E_{\text {corr }}$ between the blank and inhibited solution is less than $85 \mathrm{mV}$, showing that WS is a mixed-type inhibitor [38].

Table 2. Polarization parameters for mild steel corrosion in $0.5 \mathrm{M} \mathrm{H}_{2} \mathrm{SO}_{4}$ in the absence and presence of WS.

\begin{tabular}{|c|c|c|c|c|c|}
\hline System & $\begin{array}{c}\mathbf{E}_{\text {corr }} \\
(\mathbf{m V}(\mathbf{S C E}))\end{array}$ & $\begin{array}{c}\mathbf{I}_{\mathbf{c o r r}} \\
\left(\boldsymbol{\mu} \mathbf{A c m}^{-\mathbf{2}}\right)\end{array}$ & $\begin{array}{c}\mathbf{b}_{\mathbf{c}} \\
\left.\mathbf{( m V d e}^{-\mathbf{1}}\right)\end{array}$ & $\begin{array}{c}\mathbf{b}_{\mathbf{a}} \\
\left.\mathbf{m V d e c}^{-\mathbf{1}}\right)\end{array}$ & $\mathbf{I E ( \% )}$ \\
\hline Blank & -485.83 & 792.39 & 183.15 & 121.76 & - \\
\hline $0.2 \mathrm{~g} / \mathrm{LWS}$ & -503.35 & 124.23 & 103.45 & 68.67 & 84.32 \\
\hline $0.4 \mathrm{~g} / \mathrm{LWS}$ & -508.21 & 87.06 & 88.09 & 53.89 & 88.06 \\
\hline $0.6 \mathrm{~g} / \mathrm{LWS}$ & -513.08 & 79.06 & 83.78 & 50.78 & 89.06 \\
\hline $0.8 \mathrm{~g} / \mathrm{LWS}$ & -516.56 & 57.24 & 80.06 & 51.09 & 92.15 \\
\hline
\end{tabular}




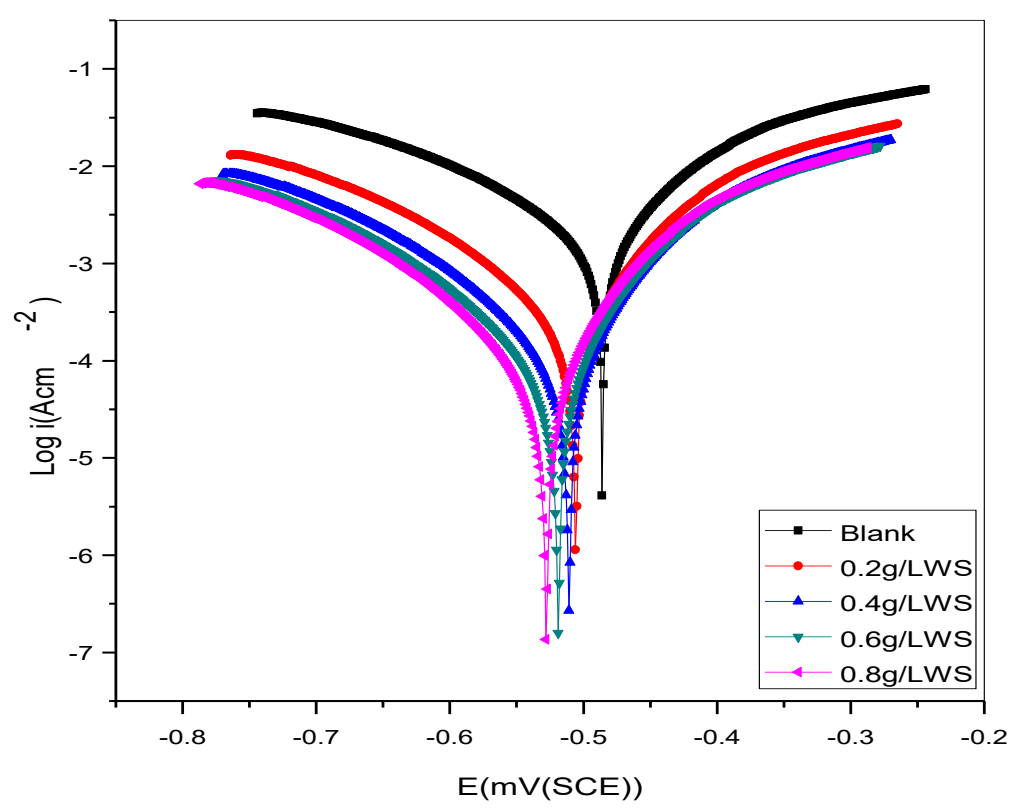

Figure 3. Polarization curves of mild steel in $0.5 \mathrm{M} \mathrm{H}_{2} \mathrm{SO}_{4}$ in the absence and presence of WS.

\section{Temperature Effect}

The temperature effect on the corrosion behavior of mild steel in the absence and presence of WS was investigated by performing gravimetric experiments at $30-60^{\circ} \mathrm{C}$ and immersion time of $5 \mathrm{~h}$. The results as shown in Table 3 demonstrate that both corrosion rate and inhibition efficiency increased with rise in temperature. This distinct behaviour exhibited WS is concentration dependent within the inhibitor concentration used in the study. The increase in inhibition efficiency with increasing temperature suggests strong adsorption interaction between the surface charge on the metal and the WS. This behavior corresponds to chemical adsorption, thus indicating that within the temperature of study there is no manifestation of adsorption-desorption phenomenon towards adsorbed inhibitor [39] on the metal surface. In addition, stability of the adsorbed inhibitor at higher temperature was not reduced despite the increase in agitation resulting from higher rates of hydrogen gas evolution [40, 41]. There is slight difference between the inhibition efficiency values of WS obtained at $6 \mathrm{~h}$ and $24 \mathrm{~h}$ immersion period respectively, thus confirming better molecular effect at elevated temperature due to more dissolution and diffusion.

Table 3. Calculated values of corrosion rate $(\mathrm{mm} / \mathrm{yr})$, inhibition efficiency $(\%)$ and degree of surface coverage $(\theta)$ for mild steel in $0.5 \mathrm{M} \mathrm{H}_{2} \mathrm{SO}_{4}$ in the absence and presence of WS at $30-60^{\circ} \mathrm{C}$ from gravimetric measurement.

\begin{tabular}{|c|c|c|c|c|c|c|c|c|c|c|c|c|}
\hline System & \multicolumn{4}{|c|}{ Corrosion rate $(\mathrm{mm} / \mathrm{yr})$} & \multicolumn{4}{|c|}{ Inhibition efficiency (\%) } & \multicolumn{4}{|c|}{ Degree of surface coverage } \\
\hline & $30^{\circ} \mathrm{C}$ & $40^{\circ} \mathrm{C}$ & $50^{\circ} \mathrm{C}$ & $60^{\circ} \mathrm{C}$ & $30^{\circ} \mathrm{C}$ & $40^{\circ} \mathrm{C}$ & $50^{\circ} \mathrm{C}$ & $60^{\circ} \mathrm{C}$ & $30^{\circ} \mathrm{C}$ & $40^{\circ} \mathrm{C}$ & $50^{\circ} \mathrm{C}$ & $60^{\circ} \mathrm{C}$ \\
\hline Blank & 62.61 & 0.02 & & 204.80 & - & - & - & - & - & - & - & - \\
\hline $0.2 \mathrm{~g} / \mathrm{L}$ & 16.71 & 23.41 & 34.01 & 44.20 & 73.31 & 3.94 & 76.03 & 78.42 & 0.73 & 0.74 & 0.76 & 0.78 \\
\hline $0.4 \mathrm{~g} / \mathrm{L}$ & 15.09 & 20.37 & 28.67 & 35.78 & 75.90 & 77.32 & 80.91 & 82.53 & 0.76 & & 0.81 & 0.83 \\
\hline $0.6 \mathrm{~g} / \mathrm{L}$ & 13.77 & 16.88 & 23.91 & 27.95 & 78.01 & 81.21 & 84.08 & 86.35 & 0.78 & 0.8 & 0.84 & 0.86 \\
\hline $0.8 \mathrm{~g} / \mathrm{L}$ & 10.26 & 13.90 & 17.54 & 21.07 & 83.61 & 84.52 & 88.32 & 89.71 & 0.84 & 0.85 & 0.88 & 0.90 \\
\hline
\end{tabular}

\section{Adsorption Isotherm Consideration}

To understand the nature of interaction between the surface charge on the metal and adsorbed inhibitor during metal corrosion, adsorption isotherm was used to explain the adsorption characteristic of the inhibitors. This is because the protective action of inhibitors depends on the 
adsorption abilities of their functional groups, molecular structure, etc. which lead to the formation protective layer the separates the metal surface from corrosion medium. Therefore, the relationship between the degree of surface coverage $(\theta)$ defined by IE/100 and inhibitor concentration (C) established by Langmuir adsorption isotherm Equation (4) was used to determine the adsorptiondesorption equilibrium constant, $\mathrm{K}_{\mathrm{ads}}$ at the different temperatures as shown below:

$$
\frac{\mathrm{C}}{\theta}=\frac{1}{\mathrm{~K}_{\mathrm{ads}}}+\mathrm{C}
$$

Plots of $\mathrm{C} / \theta$ against $\mathrm{C}$ for corrosion of mild steel in $0.5 \mathrm{M} \mathrm{H}_{2} \mathrm{SO}_{4}$ in the presence of different concentrations of WS is shown in Fig. 4.

Linear plots were obtained with slopes $1.139\left(\mathrm{R}^{2}=0.992\right), 1.117\left(\mathrm{R}^{2}=0.996\right), 1.079$ $\left(\mathrm{R}^{2}=0.998\right)$ and $1.057\left(\mathrm{R}^{2} 0.998\right)$ respectively. The calculated values of $\mathrm{K}_{\mathrm{ads}}$ obtained from the intercept are as follow: 16.406, 16.821, 18.002 and 18.904 respectively. Coefficient of linear correlation $\left(\mathrm{R}^{2}\right)$ values obtained were all above 0.991 , thus indicating a good fit of the experimental data and suggests that the adsorption of WS on metal surface followed the Langmuir adsorption isotherm.

The results show that the adsorption-desorption equilibrium constant $\left(\mathrm{K}_{\mathrm{ads}}\right)$ increased with increasing temperature, indicating better adsorption of WS onto the steel surface at elevated temperatures. In addition, at elevated temperatures adsorption-desorption equilibrium did not tend towards desorption of inhibitor from the metal surface due to enhanced molecular effect observed.

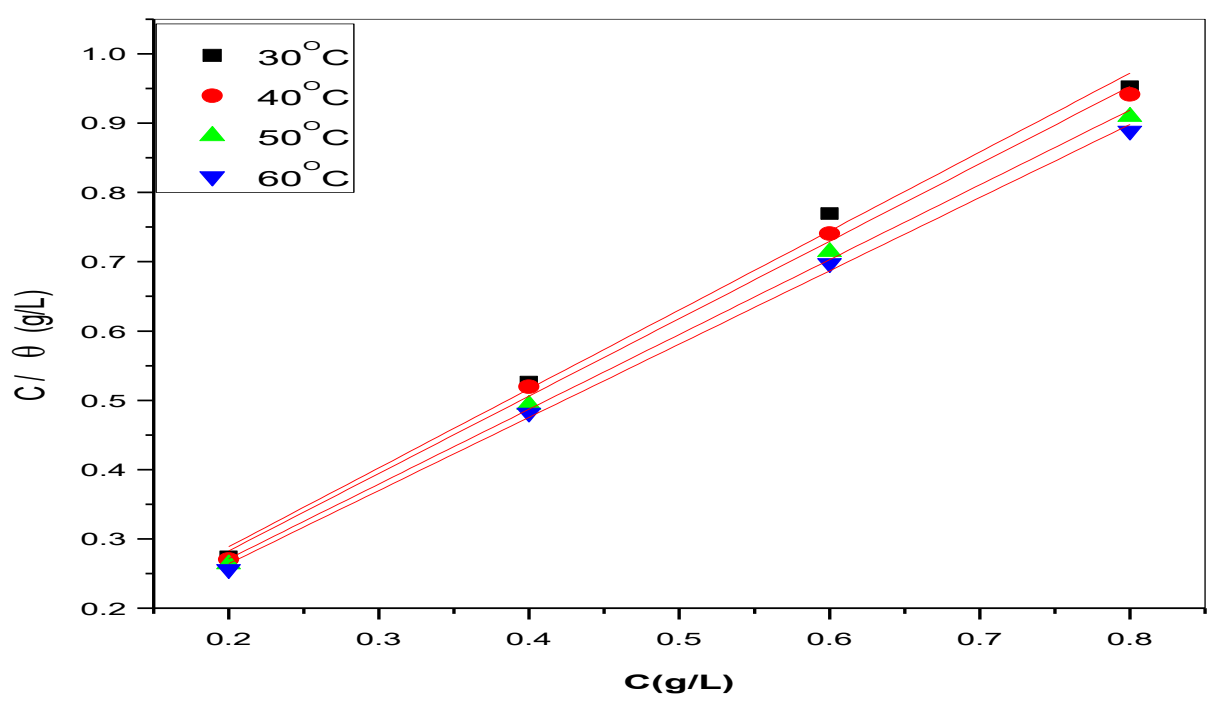

Figure 4. Plot of Langmuir adsorption isotherm for mild steel corrosion in $0.5 \mathrm{M} \mathrm{H}_{2} \mathrm{SO}_{4}$ in different concentrations of WS at different temperatures.

\section{Apparent Activation Energies}

The relationship between the rate of corrosion and apparent activation energy $\left(E_{a}\right)$ in the presence of temperature during corrosion inhibition process of metal in the absence and presence of WS was evaluated using Arrhenius Equation 5 stated below:

$$
\log \frac{\mathrm{CR}_{2}}{\mathrm{CR}_{1}}=\frac{\mathrm{E}_{\mathrm{a}}}{2.303 \mathrm{R}}\left(\frac{1}{\mathrm{~T}_{1}}-\frac{1}{\mathrm{~T}_{2}}\right)
$$

where $E_{a}$ is the apparent activation energy for the corrosion process. $C_{2}$ and $\mathrm{CR}_{1}$ are the corrosion rates at temperatures $T_{1}$ and $T_{2}$ respectively. The values of the calculated activation energy were given in Table 4. Careful inspection of Table 4 revealed that calculated values of activation energy $\left(\mathrm{E}_{\mathrm{a}}\right)$ for mild steel corrosion in $0.5 \mathrm{M} \mathrm{H}_{2} \mathrm{SO}_{4}$ in the presence of WS at different temperatures are lower than that of blank solution. Thus, indicating that WS is chemically adsorbed on the corroding mild steel surface in $0.5 \mathrm{M} \mathrm{H}_{2} \mathrm{SO}_{4}$ acidic environment. This is in agreement with the reported of 
Ekanem, et al., 2010 [42] that when the value of activation energy $\left(E_{a}\right)$ in inhibited solution is greater than that of blank solution, it shows that the inhibitor is physically adsorbed on the corroding metal surface while either unchanged or lower activation energy, $E_{a}$ in the presence of inhibitor suggests that the inhibitors are chemically adsorbed on the corroding metal surface.

\section{Heat of Adsorption Studies}

To an insight on mechanistic studies of the corrosion and inhibition process of mild steel in $0.5 \mathrm{M} \mathrm{H}_{2} \mathrm{SO}_{4}$ in the presence of WS at different temperatures, an estimate of the heats of adsorption $\left(\mathrm{Q}_{\mathrm{ads}}\right)$ was obtained from the trend of degree of surface coverage $(\theta)$ with temperature according to Equation 6 stated below:

$$
\mathrm{Q}_{\mathrm{ads}}=2.303 \mathrm{R}\left[\log \left(\frac{\theta_{2}}{1-\theta_{2}}\right)-\log \left(\frac{\theta_{1}}{1-\theta_{1}}\right)\right] \times \frac{\mathrm{T}_{1} \mathrm{~T}_{2}}{\mathrm{~T}_{2}-\mathrm{T}_{1}}
$$

where $\theta_{1}$ and $\theta_{2}$ are the degrees of surface coverage at temperature $T_{1}$ and $T_{2}$. The calculated values of the parameter are given in Table 4. Examination of Table 4 revealed that the calculated values of heat of adsorption $\left(\mathrm{Q}_{\mathrm{ads}}\right)$ for mild steel corrosion in $0.5 \mathrm{M} \mathrm{H}_{2} \mathrm{SO}_{4}$ in presence of WS at different temperatures had positive values. This is an indication that the degree of surface coverage increased with rise in temperature [43] and thus, supporting the earlier proposed chemisorption mechanism adsorption of WS on mild steel surface. In addition, the fluctuation observed in the values of $\mathrm{Q}_{\text {ads }}$ with increase in temperature is as a result of adsorption - desorption behaviour of protective film.

Table 4. Calculated values of apparent activation energy $\left(E_{a}\right)$ and heat of adsorption $\left(Q_{a d s}\right)$ for mild steel corrosion in $0.5 \mathrm{M} \mathrm{H}_{2} \mathrm{SO}_{4}$ in the presence of WS as inhibitor at $303-333 \mathrm{~K}$.

\begin{tabular}{|l|c|c|}
\hline Conc & $\begin{array}{c}\text { Activation Energy (Ea) } \\
\text { (KJ/mol) }\end{array}$ & $\begin{array}{c}\text { Heat of Adsorption } \\
\text { (KJ/mol) }\end{array}$ \\
\hline Blank & 33.145 & - \\
\hline $0.2 \mathrm{~g} / \mathrm{LWS}$ & 27.205 & 7.580 \\
\hline $0.4 \mathrm{~g} / \mathrm{LWS}$ & 24.146 & 12.107 \\
\hline $0.6 \mathrm{~g} / \mathrm{LWS}$ & 19.779 & 15.372 \\
\hline $0.8 \mathrm{~g} / \mathrm{LWS}$ & 20.126 & 15.069 \\
\hline
\end{tabular}

\section{Mechanism of Inhibition}

Corrosion inhibition of mild steel in $0.5 \mathrm{M} \mathrm{H}_{2} \mathrm{SO}_{4}$ in presence of WS can be explained on the basis of molecular adsorption [44] through the chemical constituents of starch. WS inhibits the corrosion of mild steel by controlling both the anodic and cathodic reactions. From data presented in Table 2 it is clear that WS inhibits the corrosion of mild steel by blanketing the anodic and cathodic sites. The main constituents of starch are amylose and amylopectin molecules which are partially hydrolyze to glucose units in acidic solution and the glucose units possess a number of hydroxyl $(-\mathrm{OH})$ groups and a number of aromatic rings. These organic molecules are adsorbed on the metal surface, thus forming a protective layer and hence exhibit anti-corrosive behaviour [45]. These glucose units of starch could be adsorbed on the metal/corrodent interface by one and/or more of the following ways: (i) donor-acceptor interactions between the $\pi$-electrons of aromatic ring and vacant d-orbital of surface iron atoms, (ii) interaction between unshared electron pairs of hetero atoms and vacant d-orbital of iron surface atoms, (iii) electrostatic interaction of protonated molecules with already adsorbed sulphate ions.

\section{Conclusion}

The results from weight loss measurement confirmed that control of corrosion of mild steel in $0.5 \mathrm{M} \mathrm{H}_{2} \mathrm{SO}_{4}$ using wheat starch (WS) is a feasible possible, thus indicating that WS is an efficient inhibitor for mild steel corrosion with maximum inhibition efficieny of $90.48 \%$ for $72 \mathrm{~h}$ at room temperature. The efficiency of the inhibition showed corresponding increment with increase in the 
amount of WS, thus suggesting that inhibition effectiveness of WS was concentration dependent due to adsorption on the corroding metal surface. Potentiodynamic polarization results reveal that WS acts as a mixed type inhibitor but the effect on the cathodic reactions is more predominantly controlled. The mode of adsorption of WS on the corroding metal surface was best modelled using Langmuir adsorption isotherm. In addition, the trend of inhibition efficiency with temperature, calculated values of activation energy and heat of adsorption supported the proposed adsorption mechanism. Finally, the mechanism of corrosion inhibition of mild steel using WS was attributed to the chemical constituents of starch, and results of weight loss and potentiodynamic polarization measurement are in good reasonable agreement.

\section{References}

[1] G.A. Bereket, A. Yurt, H. Turk, Inhibition of corrosion of low carbon steel in acidic solution by selected polyelectrolytes and polymers, Anti-Corrosion Methods Mater. 50 (2003) 422535.

[2] M. Mekki Daouadji, N. Chelali, Influence of molecular weight of poly (ortho-ethoxyaniline on the corrosion inhibition efficiency of mild steel in acidic media, J. Appl. Polym. Sci. 91 (2004) 1275-1284.

[3] S.K. Selvaraji et al., Corrosion behaviour of carbon steel in the presence of polyvinylpyrrolidone, Corrosion Rev. 22 (2004) 219-232.

[4] R. Manickavasagam et al., Poly(styrene sulphonic acid) doped polyaniline as an inhibitor for the corrosion of mild steel in hydrochloric acid, Anti-Corrosion Methods Mater. 49(1) (2002) $19-26$.

[5] M. Morooka et al., Effects of polymer-polymer complexes on the corrosion of mild steel in cooling water system (part 2): corrosion investigation in polymethacrylicacid/polyacrylamide system, Corrosion Eng. 50 (2001) 106-114.

[6] J. Jianguo et al., Polyvinylpyrrolidone and polyethylenimine as corrosion inhibitors for the corrosion of a low carbon steel in phosphoric acid, Corrosion Sci. 37 (1995) 975-985.

[7] A.K. Dubey, G. Singh, Corrosion inhibition of mild steel in sulphuric acid solution by using polyethylene glycol methyl ether (PEGME), Port. Electrochim. Acta. 25(2) (2007) 221-235.

[8] S.A. Umoren et al., Water soluble polymers as corrosion inhibitors of mild steel in acidic medium, Pigment and Resin Technol. 35(6) (2006) 346-352.

[9] S.A. Umoren, I.B. Obot, Polyvinyl pyrrolidone and polyacrylamide as corrosion inhibitors for mild steel in acidic medium, Surf. Rev. Lett. 25 (2008) 277-284.

[10] S. C. Nwanonenyi et al., Inhibitive performance of hydroxypropyl cellulose and potassium iodide on the corrosion of mild steel in sulphuric acid environment, American Chemical Science Journal. 16 (2016) 1-12.

[11] S.M.A. Shibli, V.S. Saji, Co-inhibition characteristics of sodium tungstate with potassium iodide on mild steel corrosion, Corrosion Science. 47 (2005) 2213-2224.

[12] E.E. Oguzie, G.N. Onuoha, A.I. Onuchukwu, Inhibitory mechanism of mild steel corrosion in 2M sulphuric acid solution by methylene blue dye, Mater. Chem. Phys. 89 (2005) 305-311.

[13] E.E. Oguzie et al., Inhibition of mild steel corrosion in sulphuric acid using indigo dye and synergistic halide additives, Mater. Chem. Phys. 84 (2004) 363-368.

[14] L. Larabi et al., Erratum to Hydrazide derivatives as corrosion inhibitors for mild steel in $1 \mathrm{M}$ HCl, Prog. Org. Coat. 54 (2005) 256-262. 
[15] S. Xia et al., Molecular dynamics and density functional theory study on relationship between structure of imidazoline derivatives and inhibition performance, Corros. Sci. 50 (2008) 20212029

[16] M.A. Shaker, H.H. Abdel-Rahman, Corrosion of copper metal in presence of binary mixtures, Am. J. Appl. Sci. 4 (2007) 554.

[17] A. Singh et al., Inhibition effect of environmentally benign Karanj (Pongamia pinnata) seed extract on corrosion of mild steel in hydrochloric acid solution, Journal of Solid State Electrochemistry. 15 (2011) 1087-1097.

[18] I.M. Mejeha et al., The inhibitive effects of Solanum melongena L. leaf extract on the corrosion of aluminium in tetraoxosulphate (VI) acid, Afr. J. Pure Appl. Chem. 4(8) (2010) $158-165$.

[19] M.A. Chidiebere et al., Corrosion inhibition and adsorption behavior of Punica granatum extract on mild steel in acidic environments: Experimental and theoretical studies, Ind. Eng. Chem. Res. 51 (2012) 668-677.

[20] E.E. Oguzie, Inhibition of acid corrosion of mild steel by Telfaria occidentalis extract, Pigm. Resin Technol. 34(6) (2005) 321-326.

[21] I.B. Obot, Z.M. Gasem, S.A. Umoren, Molecular level understanding of the mechanism of aloes leaves extract inhibition of low Carbon steel corrosion: A DFT Approach, Int. J. Electrochem. Sci. 9 (2014) 510-522

[22] S.C. Nwanonenyi et al., Experimental and theoretical studies of inhibitive behaviour of millet starch on the corrosion of aluminium in sulphuric acid environment, International Journal of Engineering and Technologies. 8 (2016) 1-13.

[23] S.C. Nwanonenyi et al., Corrosion inhibition of mild steel in sulphuric acid environment using millet starch and potassium iodide, International Research Journal of Pure and Applied Chemistry. 12(2) (2016) 1-15.

[24] H. Shokry et al., Corrosion inhibition of mild steel by schiff base compounds in various aqueous solutions: part 1, Corrosion Science. 40 (1998) 2173-2186.

[25] A. Yurt et al., Investigation of schiff bases as $\mathrm{HCl}$ corrosion inhibitors for carbon steel, Mater. Chem. Phys. 85 (2004) 420-426.

[26] S.L Granese, Study of the inhibitory action of nitrogen containing compounds, Corrosion. 44 (1988) 322-327.

[27] A.B. Tadros, B.A. Abd-El-Nabey, Inhibition of the acid corrosion of steel by 4-amino-3hydrazino-5-thio-1,2,4-triazoles, Journal of Electroanalytical Chemistry and Interfacial Electrochemistry. 246 (1988) 433-439.

[28] S. Banerjee et al., Highly efficient polyurethane ionomer corrosion inhibitor: the effect of chain structure, RSC Advances. 1 (2011) 199-210.

[29] S. Rajendran et al., Corrosion behaviour of carbon steel in polyvinyl alcohol, Anti-Corrossion Methods Mater. 52 (2005) 102-107.

[30] M. Bello, N. Ochoa, V. Balsamo, Effect of the environmental $\mathrm{pH}$ on the corrosion bioinhibitive properties of modified cassava starches, in: Proceedings of the 69th Annual Technical Conference \& Exhibition, Boston, 2011, p. 266.

[31] B.P. Charitha, P. Rao, Starch as an ecofriendly green inhibitor for corrosion control of 6061Al alloy, J. Mater. Environ. Sci. 8(1) (2017) 78-89.

[32] D. E. Arthur et al., A review on the assessment of polymeric materials used as corrosion inhibitor of metals and alloy, International Journal of Industrial Chemistry. 4(2) (2013) 1-9. 
[33] C.O. Chike-Onyegbula, O. Ogbobe, S.C. Nwanonenyi, Biodegradable polymer drilling mud prepared from guinea corn, Journal of Brewing and Distilling. 3 (2012) 6-14.

[34] C. Nawrath, Y. Poirier, C. Somerville, Plant polymers for biodegradable plastics, cellulose, starch, and polyhydroxyalkanoates, Mol. Breed. 1 (1995) 105-122.

[35] V.O. Njoku et al., Baphia nitida leaves extract as a green corrosion inhibitor for the corrosion of mild steel in acidic media, Advances in Chemistry. 2014, Article ID 808456.

[36] C.O. Akalezi et al., Mild steel protection in acidic media using Mucuna Pruriens seed extract, Int. J. Corros. Scale Inhib. 5 (2016) 132-146.

[37] S. Hu, K. Xi, C. Fu, Rice bran extraction used as pickling inhibitor in hydrogen chloride acid, J. Chin. Soc. Corros. Prot. 29 (2009) 149-153.

[38] E.S. Ferreira et al., Evaluation of the inhibitor effect of L-ascorbic acid on the corrosion of mild steel, Mater. Chem. Phys. 83 (2004) 129-134.

[39] K. Orubite-Okorosaye, N.C. Oforka, Corrosion inhibition of zinc on HCl using Nypa fruticans Wurmb extract and 1,5 diphenyl carbazone, Journal of Applied Sciences and Environmental Management. 8(2004) 56-61.

[40] S. Martinez, M. Matikos-Hukovic, A nonlinear kinetic model introduced for the corrosion inhibitive properties of some organic inhibitors, Journal of Applied Electrochemistry. 33 (2003) 1137-1142.

[41] E.E. Oguzie, Studies on the inhibitive effect of Occimum viridis extract on the acid corrosion of mild steel, Mater. Chem. Phys. 99 (2006) 441-446.

[42] U.F. Ekanem et al., Inhibition of mild steel corrosion in $\mathrm{HCl}$ using pineapple (Ananas comosus) leaf extract, Journal of Material Science. 45 (2010) 55-58.

[43] S.A. Umoren et al., Water-soluble polymers as corrosion inhibitors, Pigment and Resin Technology. 35 (2006) 346-352.

[44] S. Muthumanickam et al., Adsorption and corrosion inhibiting behavior of Passiflora foetida leaf extract on mild steel corrosion, Int. J. Corros. Scale Inhib. 4 (2015) 365-381.

[45] R.N. Nair et al., Inhibitory efficacy of Piper nigrum Linn. extract on corrosion of AA1100 in HCl, J. Chem. 3(4) (2010) 783-795. 